\title{
Condom Used Among Indirect Female Sexual Worker in Jayapura City, Papua
}

\author{
Authors \\ Antonius Oktavian, Hana Krismawati, Irawati Wieke \\ Institute of Research and Development for Biomedicine Papua \\ JlKesehatan no 10 Dok II Jayapura 99112
}

Email:ilambra@yahoo.com

\begin{abstract}
Background: HIVIAIDS still become a serious problem in the world, also in Papua Province-Indonesia. The HIV/AIDS cases in this Eastern province of Indonesia were 15.577 cumulatively in 2013 and 97,2\% of cases were heterosexual. Jayapura as the capital city of Papua Province has contributed in high number of AIDS cases, but no much data about condom used among indirect female sexual worker. The aim of this study was to determine the relationship between condom used and vaginal infection among female sexual worker in Jayapura City.

Methods: A cross-sectional design was conducted including 141 female sexual workers from bars and massage parlors who were become subjects of this study. A questioner as a tool to identified the condom used and confirmed with microscopic examination from vaginal swab. Chi-square test was used to analyze the data.

Results: This study found that $48.9 \%$ have permanent partner, $46.1 \%$ have experience condom use rejection from partner or client, 72,3\% have free condom from the clinic, 76,1\% used water based gel as lubricant. 69,5\% Indirect female sexual worker had used condom in their last sexual contact. Laboratory analysis from vaginal swab found 24,8\% have diplococcus bacteria, 2,1\% have Trichomonas vaginalis and 1,4\% Candida albicans. No relationship between condom use and laboratory test results among indirect female sexual worker.

Conclusion: More education and information about condom use is needed to raise the awareness, and will support the HIV/AIDS prevention program

Keywords: condom, HIV/AIDS, indirect female sexual worker, Papu
\end{abstract}

\section{Introduction}

Papua Province is a province with highest prevalence of HIV/AIDS in Indonesia, according Ditjen PP\&PL Ministry of Health Republic of Indonesia until March 2014 it reached 357,03 per 100.000 population. ${ }^{(1)}$ There are many risk factors contribute in HIV/AIDS transmission, but in Papua Province 97,2\% of risk factor is heterosexual HIV transmission. ${ }^{(2)}$ Jayapura City is the capital city of Papua Province with a country border with Papua New Guinea, has an airport and a harbor which become a transit city for people who want to go to the remote area of Papua Province. There are several bars and massage parlor with indirect woman sexual worker in this city. Jayapura City reach number five ranking of HIV/AIDS cases among 29 districts or cities of Papua Province. Number of 
HIV/AIDS in Jayapura City were 3.242 cases in third quarter of year 2013 cumulatively. ${ }^{(2)}$

Condom use being a part of HIV prevention in the world including Indonesia, start in Uganda at the end of 80's decade with ABC slogans contains: Abstain, $\mathrm{Be}$ faith full, Condom. ${ }^{(3,4)}$ Consist using of condom in correct way is the most efficient protection against HIV and Sexual Transmitted Infection (STI) ${ }^{(5)}$. Condom can reduces STI and also HIV until 80\% - 87\% incidences in estimated. ${ }^{(6)}$ Research in India showed that condom can reduce HIV more than $70 \%$ among female sexual worker. ${ }^{(7)}$ In Indonesia like in other countries in in the world, condom program was applied. Although the program was applied several years ago according a research in seven cities in Indonesia, condom usage among female sexual worker still low both in number and consistency with STI prevalence $89,2 \% .{ }^{(8)}$ That research revealed that condom program was not effective without adherence in usage and right technique.

Condom usage as a preventive of HIV/AIDS and other sexually transmitted diseases was applied in Jayapura City with free condom program in specific location as massage parlor, prostitute area or other high risk place. There are two type of female sexual worker, direct and indirect. Indirect sexual worker for example: massage parlor, beer girl, lap dancing, or geisha ${ }^{(9)}$ Indirect female sexual worker in Jayapura City can find in massage parlor and bars or discotheque as beer girls. There are many reasons why condom not use appropriately, such as age, socioeconomic, romantic reasons, knowledge, education, marital status of clients etc. ${ }^{(10,11)}$

In facts no much data about condom usage in Jayapura City. The aim of this study was to identified the condom usage behavior and also analyzed the relationship between condom usage with STI incidence among Indirect Female Sexual Worker in Jayapura City.

\section{Methods}

Participants: An cross sectional preliminary study, part of biobank initiation process of Institute of Research and Development for Biomedicine Papua was conduct on October November 2013. Subjects of this study were indirect female sexual workers from bars and massage parlor in Jayapura City using consecutive sampling methods. All indirect female sexual worker who had came for regular health examination in Reproduction Health Centre of Jayapura City Health Office and signed the informed consent, became subject of this study.

Measurements: A questionnaire use to identified data about demography (age, marital status, year in work as indirect sexual worker and alcohol drinking behavior), condom and lubricant usage (condom use in last sexual contact, condom usage refused from partner, condom viability in work place, broken condom experience and type of lubricant)

All the subjects had vaginal swab examination procedure in Reproduction Health Centre Clinical Laboratory of Jayapura City Health Office. Microscopic examination using gram stain to identified Candida albicans and saline solution were applied to identify other microorganism causes STI.

Data analysis: Data was analyzed in descriptive and a Chi-square with Confident Interval (CI) 95\% was used to determined the relationship between condom use and laboratory results.

Ethics: The study was reviewed by Ethics Committee of National Institute of Health and Development.

\section{Results}

A total of 141 indirect female sexual worker. Subjects had an average age of 28,9 years old and the oldest age was 53 years old. Mean of work duration in bars or massage parlor was 3 years with duration of work from 1 to 14 years. Majority of subjects choose widow as marital status $(68 \%)$ and 48,9 had permanent partners. Subjects were asked about alcohol consumption, 
more than half subjects said always or sometimes drink alcohol when they have worked, and only 19,1\% said never drink alcohol (table 1).

Table 2 shows about condom use and laboratory test results. From the table, in 1-3 days recently $107(75,9 \%)$ subjects had sexual contact, 69,5\% use condom for their sexual activity and in other hand $30,5 \%$ subjects not use condom. The most frequently reason to not used the condom in last sexual contact was: the subjects have sex with their regular partner or boyfriends $(44,2 \%)$. When faced the clients, 78,0\% subjects always suggested condom use but $46,1 \%$ had rejection. When the client rejected to use the condom, 22,0\% subjects said continued have sex contact without condom. Most subjects $(72,3 \%)$ find free condom from the clinic, $32(22,7 \%)$ subjects had experience with tear (broken) condom in use. When the condom was broken, $68,8 \%$ had changed the condom, and $12,5 \%$ said not used condom and continued sex contact. Condom lubricant gel was the most common lubricant used for sexual intercourse $(58,9 \%)$

Vaginal swab examination revealed: 39 subjects had Polymorphonuclear cell, 34 subjects with clue cell, Trichomonas vaginalis in 4 subjects, Candida albicans 2 subjects and 1 subjects with diplococcus.

Table 3 shows subjects who have sex in 7 days recently. There were 119 subjects have sex in $\leq 7$ days recently and 21 have sex more than 7 days. We analyzed the relationship between condom used in $\leq 7$ days recently with laboratory results among 109 subjects (10 subjects not test because they reject the examination or have menstrual period) and the $\mathrm{Chi}^{2}$ showed that P-value : 0,85.

Table 1. Subjects Characteristics

\begin{tabular}{ll}
\hline Characteristic & Total $(\mathbf{N}: \mathbf{1 4 1})$ \\
\hline Age (mean, range) years & $28,9(18-53)$ \\
Years in work (mean, range) years & $3,0(1-14)$ \\
Alcohol drinking $(\%)$ & \\
Never & $27(19,1)$ \\
Sometimes & $64(45,4)$ \\
Always & $50(35,5)$ \\
Marital status & \\
Not married & $35(24,8)$ \\
Married & $10(7,1)$ \\
Widow & $96(68,1)$ \\
Have partner/boyfriend & \\
Yes & $69(48,9)$ \\
\hline
\end{tabular}

Table 2. Condom Used and Laboratory Test Results

\begin{tabular}{ll}
\hline Variable & Total $(\mathbf{N}: \mathbf{1 4 1}) \%$ \\
\hline Having sex contact & \\
1-3 days ago & $107(75,9)$ \\
4-7 days ago & $12(8,5)$ \\
>7 days ago & $22(15,6)$ \\
Used condom in last sexual contact & \\
Yes & $98(69,5)$ \\
No & $43(30,5)$ \\
Suggested Partner to Use Condom & $12(8,5)$ \\
No & $19(13,5)$ \\
Sometimes & $110(78,0)$ \\
Always &
\end{tabular}




\begin{tabular}{|c|c|}
\hline \multicolumn{2}{|c|}{ Client/Partner Refused Condom } \\
\hline Yes & $65(46,1)$ \\
\hline No & $76(53,9)$ \\
\hline \multicolumn{2}{|c|}{ If Client/Partner Refused Condom } \\
\hline Rejected Sexual contact & $98 \quad(69,5)$ \\
\hline Have Sexual Contact & $31 \quad(22,0)$ \\
\hline No Answer & $12 \quad(8,5)$ \\
\hline \multicolumn{2}{|c|}{ Condom Availability in Workplace } \\
\hline Yes & $120(85,1)$ \\
\hline No & $21 \quad(14,9)$ \\
\hline \multicolumn{2}{|l|}{ Source of Condom } \\
\hline Free from Clinic & $102(72,3)$ \\
\hline Buy & $30 \quad(21,3)$ \\
\hline Client/partner & $2 \quad(1,4)$ \\
\hline Others & $7 \quad(5,0)$ \\
\hline \multicolumn{2}{|c|}{ Broken Condom Experienced } \\
\hline Yes & $32 \quad(22,7)$ \\
\hline No & $109(77,3)$ \\
\hline \multicolumn{2}{|l|}{ Type of Lubricant } \\
\hline No Lubricant & $32(22,7)$ \\
\hline Condom Gel & $83(58,9)$ \\
\hline Baby oil & $8 \quad(5,7)$ \\
\hline Body lotion & $4 \quad(2,8)$ \\
\hline Others & $14(9,9)$ \\
\hline \multicolumn{2}{|l|}{ Laboratory Test Results } \\
\hline Negative & $49(37,8)$ \\
\hline Polymorphonuclear & $39(27,7)$ \\
\hline Trichomonas vaginalis & $4 \quad(2,8)$ \\
\hline Candida albicans & $2 \quad(1,4)$ \\
\hline Clue cells & $34(24,1)$ \\
\hline Diplococcus & $1 \quad(0,7)$ \\
\hline Not test & $12 \quad(8,5)$ \\
\hline
\end{tabular}

Table 3. Relationship Between Condom Used in Recently $\leq 7$ Days and Laboratory Test Result.

\begin{tabular}{lllll}
\hline Variable & \multicolumn{2}{c}{ Laboratory Test Result } & \multirow{2}{\text{OR},}{ (CI 95\%) } & P-value \\
\cline { 2 - 3 } & Negative & Positive & \\
\hline Condom use & $30(38,0)$ & $49(62,0)$ & $0,9(0,4-2,2)$ & 0,85 \\
Yes & $12(40,0)$ & $18(60,0)$ & & \\
No & & & \\
\hline
\end{tabular}




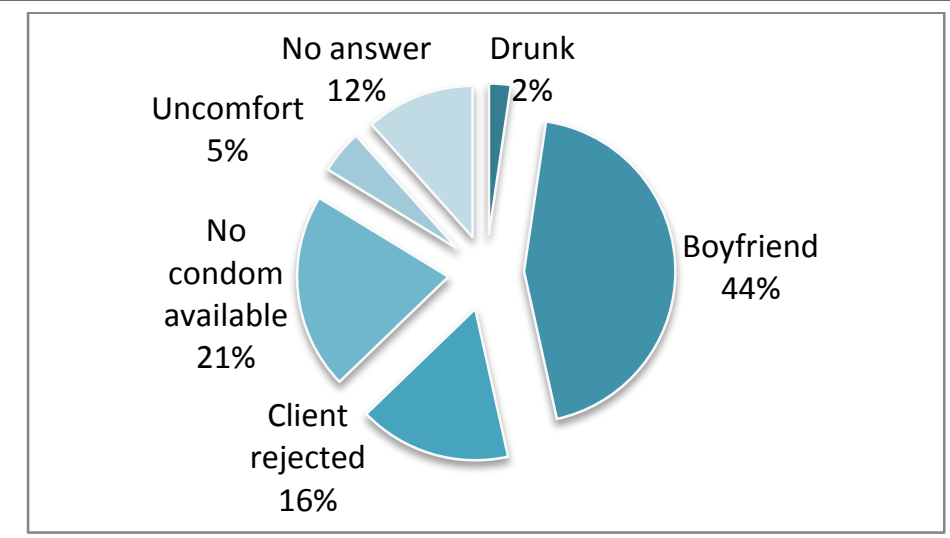

Figure 1. Chart of Reasons Not Use Condom (N: 43)

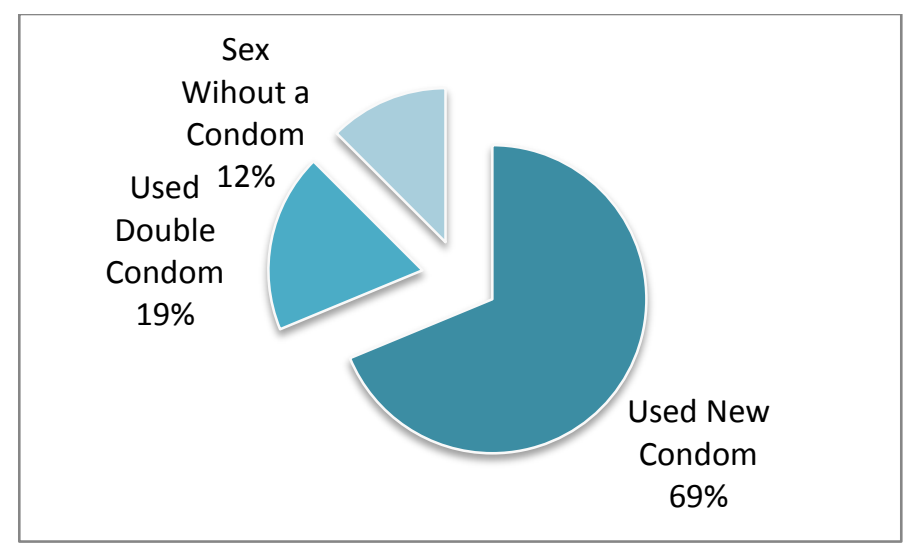

Figure 2. Chart When Condom Was Broken (N:32)

\section{Discussion}

Indirect female sexual worker in this study have mean of work duration was 3 years, and the majority subjects were widows. Different facts with researches in Gambia, Ghana and Swaziland. In Gambia showed majority subjects were widowed or separated $(69,8 \%)^{(11)}$ Meanwhile there were $70 \%$ in Ghana and $88,8 \%$ in Swaziland female sexual workers said: single and never been married in their marital status. ${ }^{(10,12)}$ Underlying reason these women became sex workers because they often did not have skills or training to be able to get alternative employment.

This study found although $85,1 \%$ had condom in their workplace and $72,3 \%$ had condom for free, but subjects who used condom in last three days when have sexual contact were less than $70 \%$. There are many factors contributing in condom use, such as: cultural, HIV and STI transmission, condom providing and also partner or clients involvement. ${ }^{(13,14)} \mathrm{A}$ research in Ghana, Kenya, Tanzania and Zambia showed that condom use affect by its availability and easy access to free condom. ${ }^{(15,16)}$ Other reasons can explain why the subjects not used the condom were: had sex with regular partners or boyfriends, partners rejected to use a condom, uncomfortable reason and had alcohol drunk. Not using a condom became an expression of trust or relationship for partners or boyfriends. ${ }^{(10)}$ In other hand reasons for many men to not using condom were: real sex means intravaginal ejaculation, penis focusing was men's sexual pleasure or afraid of losing arousal during use condom. ${ }^{(15,17)}$ When the clients rejected to use condom, 31 subjects $(22,0 \%)$ said still have sexual contact without condom. A study about condom used consistency among woman sexual worker in several city in Indonesia in 2006-2007 revealed $26,2 \%$ of subjects never used condom in one week recently. ${ }^{(8)}$ Similar with a research in Cambodia, that nineteen $(61,3 \%)$ among 31 indirect female sexual worker reported not always use condom when have sexual contact with client (not boyfriend or partner) in the last month. ${ }^{(18)}$ 
Condom use knowledge being an important thing in this study. Knowledge about condom use in correct way and how to negotiated with sex partner could increase the condom efficacy ${ }^{(19)}$ It is not easy to solved the condom use problem, related with some factors such as: socioeconomic and romance factor with partner or boyfriends. Female sexual worker who not difficult to negotiate condom use with clients were more likely consistent to use condom. ${ }^{(11)}$ In ten cities in Brazil, risk being infected by HIV increase among female sexual worker who would waive use condom on client request (difficulty in save sex negotiating) ${ }^{(20)}$

In this study condom use technique not fully understood by subjects. Several subjects use baby oil or body lotion as condom lubricant, which make the condom broken or leakage. Application of lubricants are important when using condom, it can reducing friction, prevent irritation, and add pleasurable sensations. ${ }^{(21)}$ Condom breakage or slippage reported reach $6,0 \%$ in three cities in USA. ${ }^{(22)}$ Factors contributing in condom breakage: incorrect way to opening the package, putting condom, reuse the condom, use oil based lubricant, sex intercourse position (standing up), duration, hurriedly or intensive intercourse. (23,24,25) The condom quality become also an important thing in condom program application. Four subjects said continued sex contact without condom when the condom was broken. A research in USA suggest that discomfort of condom can be a potential of antecedent of condom breakage, incomplete use and less motivation to use condom. ${ }^{(26)}$ Other characteristic can increase motivation to use condom i.e: thin, color and ribbed. $^{(27)}$ High quality condom can achieve by well design, well formulated, carefully made and to maintain that quality until the condom supplied to the user, an effective storage and distribution is needed. ${ }^{(28)}$

This research analyzed laboratory research among 109 subjects who have sex in seven days recently (total 119 subjects have sex in seven days recently, but 10 subjects have rejected the test or have menstrual period). Laboratory examination showed: 49 (37,8\%) subjects had negative results. Parasite and bacteria were found in others. A study among woman sexual worker in several big cities in Indonesia found that percentage of trichomoniasis in woman sexual worker was $10 \%$ in 2005 and 5,3\% in 2007. Gonorrhea percentage was $24 \%$ and $26,1 \%$ in 2005 and $2007 .{ }^{(8)}$ According to some research about condom's effectivity:the consistent and correct use of male latex condom can reduce HIV infection 10-20 times less than sex without condom and also reduce STI as well as genital, anal or oral infection. ${ }^{(5)}$ Condom protective as long as they prevent body fluids of partner touching mucous membrane or genitals, and do not protect against infection in uncover area (for example: ulcer on base of the penis's shaft) ${ }^{(24,29)}$

Statistical analysis showed there was no relation between condom used and laboratory result (P: $0,85)$. Reasons that it can be happened because: the value of condom used variable in this research base on subject's confession (questioner), no evidence or witness that the subjects used condom in real life. The second reason: condom misuse. Condom misuse can increase the levels of disease transmission. ${ }^{(23)}$ Research in Guatemala proved that increasing condom use among direct female sexual worker effective to reducing HIV and STI. ${ }^{(30)}$ But other research in Cambodia suggest that STI programs had limited effectiveness among indirect sex worker. ${ }^{(18)}$

Limitations to the study were: small sample size (cannot generalized on other area) and lack of information from partner of the subjects. It would be informative included sexual partner behavior and also their condom use knowledge. More research is needed to know condom usage and knowledge among clients (sexual partner) and in larger sample size.

\section{Conclusion}

Research analyzing about condom usage among indirect female sexual worker. The results suggest that there is no relationship between condom use 
in 7 days recently with vaginal swab laboratory test results. It mean though majority $(69,5 \%)$ said used condom in their recently sexual contact, but in facts only $37,8 \%$ have negative result in laboratory test.

More education and information about condom use is needed to raise the awareness, and will support the HIV/AIDS prevention program

\section{Acknowledgement}

The authors are grateful for all subjects and colleagues involved the research: Jayapura City Health Department, Clinical Laboratory of Reproduction Health.

\section{Conflicts of Interest}

The authors report no conflicts of interest in this study

\section{References}

1. Ditjen PP \& PL Kemenkes RI, HIV/AIDS Statistic Cases in Indonesia, 2014.report

2. Health Office Papua. HIV/AIDS Information Quarter III, 2013. report

3. Lammers J, Wijnbergen SJ, Willebrands D. Condom Use, Risk Perception, And Hiv Knowledge: A Comparison Across Sexes In Nigeria. HIV/AIDS - Research and Palliative Care 2013:5:283-93.

4. Steele MS, Bukusi E, Cohen CR, et al. The ABCs of HIV Prevention in Men Associations With HIV Risk and Protective Behaviors. J Acquir Immune Defic Syndr 2006;43:571-6.

5. Faculty of Sexual \& Reproductive Healthcare Royal College of Obstetricians and Gynecologists. Barrier Methods for Contraception and STI Prevention, England 2012. Manual Clinical Guidance

6. Weller SC, Davis-Beaty K. Condom Effectiveness in Reducing Heterosexual HIV Transmission (Review), 2007. Available at ://apps.who.int/rhl/reviews/CD003255.pdf
7. Mehendale SM, Gupte M, Paranjape RS et al. Declining HIV Incidence Among Patients Attending Sexually Transmitted Infection Clinics in Pune, India. J Acquir Immune Defic Syndr. 2007;45:564-9

8. Centre of Biomedicine and Pharmacy Research and Development NIHRD. STI Prevalence Among Female Sexual Worker in Kupang, Samarinda, Pontianak, Jogjakarta, Timika, Makassar and Tangerang Year 2006-2007. 2008. Report

9. Harcourt C, Donovan B. The many Faces of Sex Work. Sex Transm Infect 2005;81:201-206. doi: 10.1136/sti.2004.012468.

10. Oppong AA, Grimes RM, Ross MW, Risser J, Kessie G.Social and Behavioral Determinants of Consistent Condom Use Among Female Commercial Sex Workers in Ghana. AIDS Education Prevention 2007;19:160-72

11. Grosso AL, Lei EL, Ketende SC, et al. Correlates Of Condom Use Among Female Sex Workers In The Gambia: Results Of A Cross-Sectional Survey. PeerJ 3:e1076; DOI 10.7717/peerj.1076.

12. Yam EA, Mnisi Z, Mabusa X et al, Use of Dual Protection Among Female Sex Workers In Swaziland. International Perspectives on Sexual and Reproductive Health, 2013, 39(2):69-78, doi: $10.1363 / 3906913$.

13. Denue BA, Kwayabura SA, Bukbuk D, Inuwa U, Ajayi BB. Evaluation of Condom Use and Associated Factors among Adult HIV Clients in Maiduguri, North Eastern Nigeria: A Comparative Cross Sectional Study. World J AIDS. 2014: 4: 169-17.

14. Stutterheim SE, Bertens MG, Mevissen FE, Schaalma HP. Factors Contributing to Inconsistent Condom Use Among Heterosexual Men in Curaçao. Cult Health Sex 2013;15:420-33. 
15. Flood M. Addressing The Sexual Cultures of Heterosexual Men: Key Strategies inInvolving Men and Boys in HIV/AIDS Prevention. United Nations.EGM/MenBoys-GE/2003.Report

16. Sandoy IF, Blystad A, Shayo EH, et al. Condom Availability In High Risk Places And Condom Use: A Study At District Level In Kenya, Tanzania And Zambia. BMC Public Health 2012; 12:1030.

17. Sanders SA, Hill BJ, Crosby RA et al. Correlates of Condom-Associated Erection Problems in Young, Heterosexual Men: Condom Fit, Self-Efficacy, Perceptions, and Motivations. AIDS Behav. 2014; 18(1): 128-34.

18. Kim AA, Sun LP, Chhorvann C, et al. High Prevalence of HIV and Sexually Transmitted Infections Among Indirect Sex Workers in Cambodia. Sex Tras Dis. 2005;32;745-51.

19. Wirtz AL, Schwartz S, Ketende S et al. Sexual Violence, Condom Negotiation, and Condom Use in the Context of Sex Work: Results From Two West African Countries. J Acquir Immune Defic Syndr 2015; 68(2): 171-9

20. Damacena GN, Szwarcwald CL, Souza PRB, et al. Risk Factors Associated With HIV Prevalence Among Female Sex Workers in 10 Brazilian Cities. J Acquir Immune Defic Syndr 2011;57: 144-52.

21. Gannet Health Service. Condoms and Lubricants. Cornell University https://www.gannett.cornell.edu/cms/pdf/s exual/upload/Condoms_Lube.pdc. Access: September 1, 2015.Web

22. D'Anna LH, Korosteleva O, Warner L et al. Factors Associated With Condom Use Problems During Vaginal Sex With Main and Non-main Partners. Sex Transm Dis. 2012 ; 39(9): 687-93

23. Hawangchu D, Chamratrithirong A. Factors Associated With Condom
Breakage Among Men In The Kanchanaburi Demographic Surveillance System, Thailand. The 2009 Population Association of America Annual Meeting, April 29 - May 2, Detroit, MI, USA. Paper.

24. International Planned Parenthood Federation.UNFPA. Myths, Misperceptions and Fears: Addressing Condom Use Barrier. 2007. New York. Booklet.

25. Bradley J, Rajaram S, Alary $M$ et al. Determinants of Condom Breakage Among Female Sex Workers in Karnataka India. BMC Public Health 2011, 11(Suppl 6):S14.

26. Crosby R, Yarber WL, Sanders SA, Graham CA. Condom Discomfort and Associated

Problems With Their Use Among UniversityStudents. J Am Coll Health 2005; 54(3) : 143-7.

27. Burke RC, Wilson J, Kowalski A et al. NYC Condom Use and Satisfaction and Demand for Alternative Condom Products in New York City Sexually Transmitted Disease Clinics. Journal of Urban Health: Bulletin of the New York Academy of Medicine.2011; 88(4): 749-58.

28. UNAIDS. The Male Latex Condom.http://data.unaids.org/Publication s/IRC-pub01/JC003-MaleCondom-

FactSheets_en.pdf. Access: September 1, 2015. Web.

29. USAID. Condom Use: How It Relates To HIV and STI Prevention. September 2013.Manual.

30. Sabido M, Giardina F, Hernandez G et al. The UALE Project: Decline in the Incidence of HIV and Sexually Transmitted Infections and Increase in the Use of Condoms Among Sex Workers in Guatemala. J Acquir Immune Defic Syndr 2009;51:35-41 